\title{
Smartphone addiction among Qatar University students: a cross-sectional study
}

\section{Reem Ashour, Sana Elashie, Bayan Alkeilani, Mujahed Shraim}

\begin{abstract}
Background
Smartphone addiction (SPA) is an important emerging public health problem. SPA is defined as excessive smartphone use, which is associated with functional impairment in activities of daily living and substance dependence-like-symptoms. ${ }^{1}$ A growing number of studies fatalities, ${ }^{2.3}$ higher stress scores, ${ }^{4}$ anxiety and depression disorders ${ }^{6}$ poor social relationships, 7 sleep disturbance, ${ }^{8-9}$ low physical activity, $10-11$ and fast food consumption and weight gain. 11 Prior research suggests that adoloscents and colloge students tend to use the genes popultion Prior respect to the relationship between SPA and academic perfomance among college studies ${ }^{12-14}$ Other studies reported that SPA among college students was associated with higher stress scores, higher anxiety and depression scores, ${ }^{15-16}$ inadequate sleep duration, ${ }^{16-17}$ and negative health related behaviors, such as eating more fast food, lower levels of physical exercise, and increase in body weight." ${ }^{11}$ This highlights the importance of research examining risk factors for SPA and the mechanisms underlying the potential relationships between SPA with negative health outcomes and lower academic

In Qatar, recent estimates show that $95 \%$ of the general population and $98 \%$ of people aged $18-24$ years reported using a smartphone. However, the prevalence of SPA among college students in Qatar is unknown. Additionally, no prior studies have examined the potentia behaviors, and psychological well-being among undergraduate students in Qatar. Identifying characteristics of students at risk of SPA and the extent of SPA impact on academic performance and health and psychological well-being may shed light on potentia
\end{abstract}

Aim

The aims of this study were to (I) estimate the prevalence of SPA among students in Qatar University (QU); (II) assess the correlaton between daily duration of smartphone use (SPU) and SPA; (II) assess the relationship between SPA with (a) current Grade point Average (GPA). (b) psychological distress, and (c) studen performance, sleep at night, social activity, and physical and menta pealth

\section{Methods}

We used a cross-sectional study using a self-administered electronic or paper questionnaire. All undergraduate and graduate studen registered in QU during Fall 2019 were included. The first part of the questionnaire collected the following information: age, gender, nationally (Qatan, Bache (f, Master, Ph t), year of study (1st to ohr year), employm moderate physical exercise of 10 minutes performed in the pas week (none, $1-4$ days/week, 5-7 days/week), history of doctordiagnosed chronic diseases (yes, no), current GPA, and daily duration of smartphone use in hours.

The second part of the questionnaire measured SPA using the Smartphone Addiction Scale (SAS), which is a self-administere questionnaire that has been validated in English and Arabic. ${ }^{1-20}$ The they disagree or agree with the 10 standements a what extent do they disagree or agree with the 10 statements about their current (strongly disagree, disagree, weakly disagree, weakly agree, agree strongly agree). The overall SAS score ranges between 6 and 60 (higher scores indicate higher level of SPA), and scores $\geq 33$ in females and $\geq 31$ in males are classified as "SPA". The third part the questionnaire used the General health Questionnaire 28 (GHQ28) to measure the likelihood of student having "psychologic distress". The GHQ-28 has been validated in English and Arabic. ${ }^{21}$ The GHQ-28 measures the frequency of experiencing 28 behaviora items using a 4-point scale $(0=$ "not at all, $1=$ "no more than usual, overall GHO-28 score ranges between 0 and 84 (higher scores indicate higher level of psychological distress), and scores $\leq 23$ are classified as "psychological distress". The fourth part of the questionnaire asked the participants to indicate to what extent do they disagree or agree (6-point Likert scale) with 10 statements (Figure 2) about their perceived impact of smartphone use on their academic performance, learning, sleep at night, social activity, and

Descriptive statistics were used to summarize the data. Multivariable logistic and linear regression analyses were performed to examine the relationships between the predictor and the outcome variables. completion method (paper and electronic) to assess for potentia selection, response, and social acceptability biases. All analyses were performed using IBM SPSS statistics V2
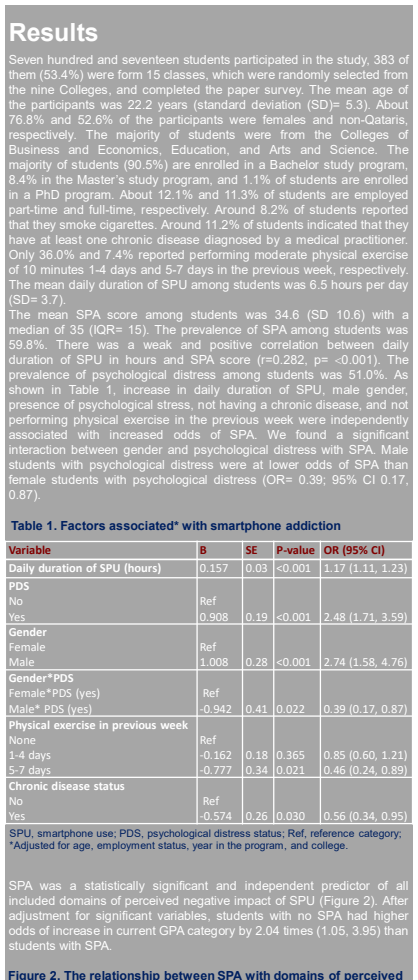
negative impact of SPU
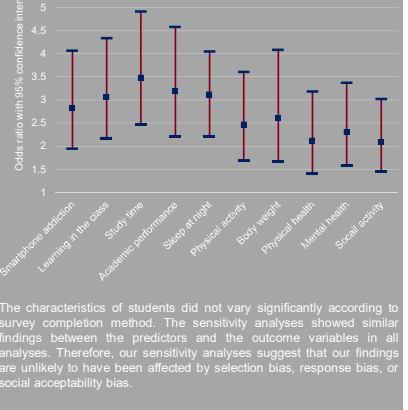

\section{Conclusion}

SPA is highly prevalent among QU students. SPA or longer duration of SPU have negative impact on academic performance, psychological distress, and perceived physical and mental health, not clear. Further longitudinal research with mixed designs is required to examine the direction of associations and identify potential causing mechanisms. Such information could be used to design and test intervention to prev

\section{References}

1. Billieux J, Maurage P, Lopez-Fernandez O, DKuss DJ, Grifiths MD. An Update on Current Evidence and a Comprehensive Model for Future

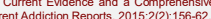

2. Kim HJ, Min JY, Min KB. Accident risk associated with smartphone

3. Zatezalo N, Erdogan M, Green RS. Road Traffic Injuries and Fatalities among Drivers Distracted by Mobile Devices. J Emerg Trauma Shock.

4. A conceptual overview and systematic review of relations with anxiety and depression psychopathology. JAffect Disord. 2017;207:251-9.
C. Elhai JD. Levine JC. Hall BJ. The relationship between anxiety 6. Elhai JD, Levine JC, Hall BJ. The relationship between anxiety
symptom severity and problematic smartphone use: A review of the slmptom severity and problematic smartphone use: A review of
literature and conceptual frameworks. J Anxiety Disord. 2019;62:45-52. 7. Hawi NS, Samaha M. Relationships among smartphone addiction,
anxiety, and family relations. Behav Inf Technol. 2017;36(10):1056-2. Thomé S, Harenstam A, Hagberg M. Mobile phone use and stress, sleep disturbances, and symptoms of depression among young adults--a

9 Munezawa T, Kaneita Y, Osaki Y, Kanda H, Minowa M, Suzuki K, et at. The association between use of mobile phones after lights out and sleep disturbances among Japanese adolescents: a nationwide cross-sectional

10. Venkatesh E, Jemal MYA, Samani ASA. Smart phone usage and
10.

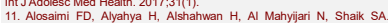
Smartphone addiction among university students in Riyadh, Saudi Arabia. Saudi Med J. 2016:37(6):675-83.
12. Lepp A, Barkley JE, Karpinski AC. The Relationship Between Cell 12. Lepp A, Barkley JE, Karpinski AC. The Relationship Between Cell
Phone Use and Academic Performance in a Sample of U.S. College Students. SAGE Open. 2015;1(January - March):1-9.

13. Boumosleh MJ, Jaalouk D. Depression, anxiety, and smartphone addiction in university students- A cross sectional study. PLoS One. 14. Samaha M, Hawi N. Relationships among smartphone addiction, stress, academic performance, and satisfaction with 15. Zhang MWB, Lim RBC, Lee C, Ho RCM. Prevalence of Internet Addiction in Medical Students: a Meta-analysis. Acad Psychiatry. 2018:42(1):88-93.

16. Albursan IS, Al Qudah MF, Dutton E, Hassan EMAH, Bakhiet SFA Ymartphone Addiction: A Study of Students in Jordan, Saudi Arabia,
Yemen and Sudan. Community Ment Health J. 2019. 17. Aljomaa SS, Al.Qudah MF, Albursan IS, Bakhiet SF, Abduljabbar AS. Smartphone addiction among university students in the light of some
variables. Computers in Human Behavior 2016:61(2016): 155-64. 18. Northwestern University in Qatar. Media use in the Middle East, 2016:
Online and social media 2016 [Available from: Online
http $J /$ i 19. Kwon M, Kim DJ, Cho H, Yang S. The smartphone addiction scale:
(a) development and validation of a shor vistion for adolescents. PLoS One

20. Stendla A, Laita M, Nejjar B, Souirti Z, Touhami AAO, Senhaji M. Addiction Scale-Short Version in Addiction Scale and Smartphone Cyberpsychol Behav Soc Netw. 2018;21(5):325-32. 21. Goldberg DP, Williams P. A user's guide to the General Health 22. Alhamad A, Al-Faris EA. The validation of the general health Community Med. 1998;5(1):13-9.

\section{Acknowledgement}

We would like to thank all students for their participation and making this study feasible. We thank the faculty members for facilitating dat $20 \mathrm{~s})$

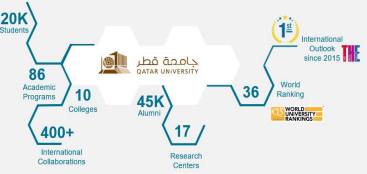

